\title{
HOMOTOPY PERTURBATION METHOD TO FRACTIONAL BIOLOGICAL POPULATION EQUATION
}

\author{
YANQIN LIU, ZHAOLI Li AND YUEYUN ZHANG
}

\begin{abstract}
In this paper, the Homotopy perturbation method is successfully extended to solve fractional biological population model and numerical results are obtained. The fractional derivatives are described in the Caputo sense, some examples are provided. And the solutions of the equation are continuous with the parameter $\alpha$.
\end{abstract}

Mathematics subject classification (2010): 35D99.

Keywords and phrases: Homotopy perturbation method, biological population model, Caputo derivative, Mittag-Leffler function.

\section{REFERENCES}

[1] S. Z. RIDA, A. A. M. ARAFA, Exact solutions of fractional-order biological population model, Commun. Theor. Phys., 52 (2009), 992-996.

[2] R. HILfER, Applications of fractional calculus in physics, World scientific, Singapore, 2000.

[3] J. H. HE, Homotopy perturbation technique, Comput. Methods Appl. Mech. Eng., 178 (1999), $257-$ 262.

[4] J. H. HE, A coupling method of a homotopy technique and a perturbation technique for non-linear problems, Int. J. Non-linear Mech., 35 (2000), 37-43.

[5] J. H. HE, The homotopy perturbation method for nonlinear oscillators with discontinuities, Appl. Math. Comput., 151 (2004), 287-292.

[6] J. H. HE, Application of homotopy perturbation method to nonlinear wave equations, Chaos Soliton Fract., 26 (2005), 695-700.

[7] X. Y. Jiang, M. Y. XU, Analysis of fractional anomalous diffusion caused by an instantaneous point source in disordered fractal media, Int. J. Nonlinear Mech., 41 (2006), 156-165.

[8] X. C. LI, M. Y. XU, X. Y. JiANG, Homotopy perturbation method to time-fractional diffusion equation with a moving boundary condition, Comput. And maths. With Appl., 208 (2009), 434-439.

[9] R. METZLER, J. KLAFTER, The random walks guide to anomalous diffusion: a fractional dynamics approach, Phys. Rep., 339 (2000), 1-77.

[10] S. MOMANI, Z. ODIBAT, Homotopy perturbation method for nonlinear partial differential equations of fractional order, Phys. Lett. A, 365 (2007), 345-350.

[11] Z. OdiBAt, S. Momani, Modified homotopy perturbation method: application to quadratic Riccati differential equation of fractional order, Chaos Soliton Fract., 36 (2008), 167-174.

[12] I. Podlubny, Fractional differential equations, Academic Press, New York, 1999.

[13] E. ShaKeri, M. Dehghan, Numerical solutions of a biological population model using He's variational iteration method, Comput. And maths. With Appl., 54 (2007), 1197-1207.

[14] S. W. WANG, M. Y. XU, Axial couette flow of two kinds of fractional viscoelastic fluids in an annulus, Nonlinear Anal: Real World Appl., 10 (2009), 1087-1096.

[15] Q. WANG, Homotopy perturbation method for fractional KdV-Burgers equation, Chaos Soliton Fract., 35 (2008), 843-850. 